\title{
A FILOSOFIA DA EDUCAÇÃO NO GIRO DO RECONHECIMENTO DO OUTRO
}

\author{
Amarildo Luiz Trevisan* \\ Catia Piccolo Viero Devechi* \\ Geraldo Antonio da Rosa** \\ André Luiz de Oliveira Fagundes ${ }^{* * * *}$
}

\begin{abstract}
Resumo
O presente texto oferece subsídios para a compreensão da virada do reconhecimento na teoria crítica, a qual introduz a figura do outro como categoria-chave da sua atuação. Assim como os pioneiros da Escola de Frankfurt, Habermas e Honneth constituem-se em fontes importantes para pensar alguns conceitos nesse sentido, tais como a comunicação, a reificação, o reconhecimento e, em última instância, o reconhecimento das diferenças. A partir do giro do reconhecimento, a teoria crítica dá-se conta de que não basta mais denunciar os males da reificação causados pelo avanço da razão instrumental, é preciso anunciar possibilidade de transcendê-los a partir de uma reconstrução teórica estruturada na busca de ações de entendimento. O desafio do artigo é debater o avanço na crítica a posturas reificadas, que não permitem a consideração ao lugar do outro, da alteridade e das diferenças, em plenitude, na relação entre filosofia e educação.
\end{abstract}

Palavras chave: Teoria crítica. Reconhecimento do outro. Filosofia da educação.

* Doutor em Educação pela Universidade Federal Rio Grande do Sul (UFRGS). Professor do Programa de Pós-Graduação em Educação da Universidade Federal de Santa Maria (UFSM) e pesquisador do CNPq. E-mail: trevisanamarildo@gmail.com

** Doutora em Educação pela Universidade Federal de Santa Catarina (UFSC). Professora do Programa de Pós-Graduação em Educação da Universidade de Brasília (UnB). E-mail: devechi@unb.br

*** Doutor em Teologia: Religião e Educação pela Escola Superior de Teologia (EST/São Leopoldo-RS). Professor do Programa de Pós-Graduação em Educação da Universidade de Caxias do Sul (UCS).E-mail: garosa6@ucs.br

${ }^{* * * *}$ Mestre em Educação pela Universidade Federal de Santa Maria (UFSM). Doutorando pelo Programa de Pós-Graduação em Educação da Universidade Federal de Santa Maria (UFSM).E-mail: andrelive@bol.com.br 


\begin{abstract}
The present text offers subsidies to understand the recognition turn in critical theory, which introduces the figure of the other as key category of its performance. Like the pioneers of the Frankfurt School, Habermas and Honneth constitute themselves as important sources to think some important concepts in this sense, such as communication, reification, recognition and, ultimately, the recognition of the differences. Based on the recognition turn, critical theory realizes that it is no longer enough to denounce the evils of the reification caused by the advancement of the instrumental reason, it is necessary to announce possibility of transcending them from a theoretical reconstruction structured in searching for actions of understanding. The challenge of the article is to discuss advances in critical to reified postures, that do not allow consideration to the place of the other, to the otherness and to the differences in fullness, in the relationship between philosophy and education.
\end{abstract}

Keywords: Critical theory. Recognition of the other. Philosophy of education.

\title{
Considerações iniciais
}

A emblemática viagem de Ulisses, da Odisséia de Homero, retomada por Adorno e Horkheimer na Dialética do esclarecimento procura mostrar que a razão ocidental, ao encetar o seu rumo na conquista da natureza exterior, precisou se fechar ao encanto das sereias, negando desse modo a si mesmo, à dimensão do outro e das diferenças. Por isso Ulisses não sai diferente da experiência vivida, pois o outro era visto como um oponente que precisava ser vencido. Este episódio é pródigo em mostrar o trabalho teórico dos pioneiros da Escola de Frankfurt, quando denunciam a impossibilidade da razão instrumental de dialogar com o outro e o estranho. Tal apontamento é indicado como o grande problema da racionalidade ocidental, uma vez que a razão se tornara cega à experiência com a alteridade e as diferenças, as quais não causam sinal algum de mudança no herói. Além disso, mostra também que a teoria crítica desde a sua origem guarda um vínculo secreto com as origens da trajetória da racionalidade ocidental, por se reportar às tradições clássicas para melhor entender fenômenos tipicamente modernos. 
No entanto, embora continuadores dessa tradição, Habermas e Honneth cultivam outra visão desse processo, defendendo uma ampliação do diálogo com o outro como a condição para a produção de significados. Há um deslocamento do eixo de gravidade da discussão da história e, principalmente, da filosofia da história ${ }^{1}$ para o ângulo de compreensão dos processos sociais como sistema normativo capaz de revelar novas possibilidades para a teoria crítica. Ela deixa de acontecer em torno da relação sujeito conhecedor e objeto a ser conhecido, em favor das relações intersubjetivas dos sujeitos que buscam se entender sobre algo no mundo. Nesse sentido, o giro do reconhecimento aludido refere-se à retomada do aspecto normativo da teoria em direção ao outro, advogado enquanto instância capaz de produzir entendimentos para estabelecer as condições de uma vida boa ou não fracassada.

Honneth, por exemplo, lança mão de outra metáfora, já utilizada por Hegel, para explicar a dialética do espírito no movimento do reconhecimento, presente na famosa passagem da Fenomenologia do espírito, no momento em que o senhor se descobre dependente do escravo. O componente subversivo na ideia do reconhecimento oferece contributos para a teoria crítica, porquanto o escravo se submete ao seu senhor não apenas pelas relações de dominação e servilismo, mas também de estima, consideração e reverência. Enquanto o escravo se descobre forte, o senhor se percebe frágil, pois a verdade deve passar pelo veredicto do outro. A teoria crítica se compreende, então, fazendo parte do contexto pós-metafísico e falibilista, tendo que fazer não apenas a denúncia, mas principalmente acertos junto ao outro no mundo.

1 Embora a crítica à filosofia da história não possa ser considerada um problema já resolvido por Habermas e Honneth, no entanto é possível anotar que os pioneiros da Escola de Frankfurt, ao se contrapor ao espírito historicista - que consistia em fazer a leitura dos fatos históricos e prever ou fazer vaticínios futuros - propuseram uma leitura às avessas desse processo, expressa na famosa metáfora de Walter Benjamin: "escovar a história a contrapelo". Com isso, ainda há uma crença numa filosofia da história, uma filosofia da história particular, ou sui generis, por que dar um passo em direção ao progresso significa que o homem se depara com o retrocesso à barbárie, como bem ficou evidente na análise de Benjamin do quadro, de Paul Klee, "Angelus Novus". Daí surge a recusa a qualquer teleologia, fragilizando a teoria no seu aspecto normativo, pois não há mais um fim a ser buscado, dado que este pode levar à catástrofe dos campos de concentração nazista. Ver a este respeito, a comparação que Honneth faz da filosofia da história de Kant com as teses sobre a filosofia da história de Walter Benjamin (HONNETH, 2008). 
A percepção da fragilidade da filosofia do sujeito, a que a teoria crítica já denunciava, leva à abertura ao diálogo, à conversação e à autocrítica.

A verdade não precisa mais atravessar de um lado a outro do oceano com uma certeza prévia intocada, mas no caminho se abre à dimensão do outro e do estranho e por isso pode chegar, a seu termo, modificada. O diferencial da leitura realizada por cada uma das apropriações da teoria crítica está na complementação do giro reconhecimento, que coloca o diferente (o outro do diálogo) como vetor importante para a validação do saber. Enquanto à teoria crítica coube inicialmente denunciar essa impossibilidade no contexto da reificação, o giro do reconhecimento tenta mostrar a incompletude da experiência humana que acaba se modificando no seu acontecer, não por razões estratégicas ou metodológicas simplesmente, mas por condições vividas na interação com o outro.

A partir da elevação do "outro" à categoria central para pensar os procedimentos pedagógicos, muda-se o tratamento dado à história do conhecimento, à perspectiva da inclusão social e ao desenvolvimento de identidades, tornando mais sensíveis as experiências de não reconhecimento. Essa mudança não é de modo algum casual, mas acompanha um movimento mais amplo ocorrido na cultura contemporânea, mapeado por Sousa Santos (1989) como tendo o objetivo de desdogmatizar os objetos teóricos da ciência, mas, principalmente, chamar a atenção para o fato de que as lutas são travadas no campo das argumentações e de que essas são condições para a produção de verdades.

Porém, tendo em vista o horizonte do giro compreensivo, como pensar a relação entre filosofia e educação? Como a filosofia da educação pode ser identificada normativamente nesse novo contexto, de descentramento de perspectivas e de pluralidade de visões de mundo? Neste artigo, pretendemos apresentar o desenvolvimento da teoria crítica a partir da sua gradativa aproximação com o viés compreensivo do reconhecimento do outro, principalmente na perspectiva de Habermas e Honneth. Neste sentido, o texto oferece subsídios para que o interlocutor compreenda a discussão de acordo com as seguintes fases: 1) Retomada do reconhecimento no amplo giro hermenêutico da teoria crítica; 2) Discussão sobre a relação da teoria de Habermas com a proposta de luta por reconhecimento, de Honneth; 3) Análise da categoria marxista da reificação, segundo Honneth, como experiência de não reconhecimento; 4) Definição de tarefas da filosofia da educação no novo contexto. 
A partir da elevação do "outro" à categoria central para pensar os procedimentos pedagógicos, muda-se o tratamento dado à história do conhecimento, à perspectiva da inclusão social e ao desenvolvimento de identidades, tornando mais sensíveis as experiências de não-reconhecimento.

\section{Retomada do reconhecimento na teoria crítica}

Desde a fundação do Instituto de Pesquisa Social, em 1924, por Horkheimer e Pollock aos dias de hoje, a crítica social frankfurtiana sofreu consideráveis modificações em seu núcleo teórico, o qual esteve inicialmente assentado nas premissas de Marx e do freudismo. Os pensadores de Frankfurt, ao criticar o processo de racionalização sob as condições de vida do sujeito, procuraram evitar a ênfase excessiva na categoria trabalho e na racionalidade de troca, numa forma de transpor o caminho iniciado por Marx. O objetivo foi estender a crítica a outros aspectos da vida social, esclarecendo as imbricações entre os aspectos econômicos da sociedade, a vida psíquica do sujeito e as mudanças no domínio da cultura. Para eles, havia uma forma de razão comprometida apenas com os fins do capital que invadia outras esferas da vida, penetrando nos meios de comunicação de massa, no ambiente de trabalho e nas instituições sociais. Identificaram, então, no desenvolvimento da própria razão uma dimensão instrumental que se sobrepunha ao potencial de emancipação presente na racionalidade crítica. Desse modo, o desenvolvimento tecnológico representou também regressão e submissão do indivíduo a formas de pensar incompatíveis com a conquista de sua maioridade. Daí em diante, já estava denunciada a existência de um elemento regressivo na própria razão esclarecida, quando esta abandona a crítica sobre si mesma.

Segundo Jimenez, o empreendimento dos pioneiros de Frankfurt se volta "à gênese do logos", no mundo grego, para compreender o gesto primeiro de afirmação absoluta de confiança na razão. Por isso, baseado nessa filosofia, ele pergunta:

Como pode a razão, princípio superior em nome do qual a filosofia das Luzes elaborou os maiores ideais da humanidade, direitos do homem, liberdade, justiça e igualdade, inverter-se num fabuloso instrumento de dominação capaz de subjugar tanto a natureza quanto os próprios homens? (JIMENEZ, 1999, p. 354). 
Trata-se de um questionamento ao modelo totalitário de razão que introduz críticas acerca dos significados normativos predeterminados que padronizam e manipulam as manifestações da vida humana. Essas críticas desautorizam o desenvolvimento de novas formas reguladoras, uma vez que o diagnóstico da reificação não deixa espaços para projeções utópicas, afinal tudo estava contaminado pela dominação do mundo administrado. Mas poderíamos nos perguntar o que significaria nesse contexto a virada do reconhecimento na teoria crítica?

Nesses termos, o giro do reconhecimento da teoria crítica pode ser traçado, sobretudo, a partir do momento em que Habermas, representante da segunda geração dos frankfurtianos, se propõe a reconstruir, no horizonte da linguagem, as premissas da racionalidade criticada pelos seus antecessores (especialmente Adorno e Horkheimer). Com isso, o foco se desloca da esfera da subjetividade para a intersubjetividade e vai consolidando, progressivamente, uma nova visão interpretativa das patologias sociais, dirigida à preocupação com o outro. Essa guinada na teoria crítica (HOLMES, 2009) se aprofunda, principalmente no momento em que aparece nesse contexto a ênfase na categoria do conflito, expressa na ideia de luta por reconhecimento, conforme Axel Honneth desenvolve a partir de Hegel.

Retomando essa questão, podemos dizer que, embora estivesse se encaminhando para um afastamento das teses originais de Marx, ainda assim, a centralidade da crítica de Adorno e Horkheimer residia em torno da denúncia aos efeitos da racionalidade instrumental no contexto do mercado e do progresso técnico da ciência, enquanto dominação do homem. Desse modo, ainda pesava, de forma bastante expressiva, a categoria trabalho e as suas relações com os mecanismos da produção e do sistema. Daí a ênfase recorrente desses pensadores na demonstração das condições reificantes do sujeito inserido no contexto da vida moderna, regida pelo capitalismo do século XX.

\section{A busca do entendimento no mundo da vida}

Habermas transpõe os fundamentos procedentes de Marx presentes no berço da teoria crítica. Depois dele não será apenas o trabalho a condição fundamental por meio da qual o homem se afasta da dominação da natureza, se historiciza e conquista sua emancipação, mas, sobretudo, a comunicação. Para ele, o homem não é só aquele que opera ou labora diante das necessi- 
dades do mundo sistêmico, mas também aquele que se comunica perante o mundo da vida. Nesse sentido, o ser social deve perseguir não apenas o conflito aos sistemas redigidos pelas categorias políticas e econômicas, mas também os acordos regidos pelos pressupostos da convivência e interação humana. Tal "giro" da comunicação empreendido por Habermas tem como efeito direto uma reconstrução da racionalidade, calcada em alicerces intersubjetivos. Trata-se de uma racionalidade comunicativa que

traz consigo conotações que, no fundo, retrocedem à experiência central da força espontaneamente unitiva e geradora de consenso própria da fala argumentativa, em que diversos participantes superam suas concepções inicialmente subjetivas e então, graças à concordância de convicções racionalmente motivadas, asseguram-se ao mesmo tempo da unidade do mundo objetivo e da intersubjetividade de seu contexto vital (HABERMAS, 2012, p. 36).

Com isso, o fulcro de sustentação da sociedade não se situa mais no esquema das relações de produção, de sujeito e objeto, antes disso está nas relações de compreensão e comunicação linguística. Com efeito, a substancialidade da estruturação social deixa de ser visada apenas pelo aspecto da ação instrumental para ancorar-se numa ação comunicativa. Justamente nesse momento, abre-se margem para a possibilidade de se chegar ao consenso, mediante o potencial da racionalidade discursiva, a qual procura apoio numa nova base de sustentação das relações sociais, a saber, a normatividade da razão comunicativa. Portanto, para Habermas o sujeito é, antes de tudo, comunicativo e busca o consenso, por meio de "atos de fala", ancorados por um "saber de regras", que assegura o significado resultante de acordos instituídos por uma comunidade de interlocutores que argumentam constantemente.

A mudança se dá em Habermas na tentativa de recuperar a razão que estava dominada pelo mundo sistêmico, referendando a racionalidade comunicativa orientada pelo mundo da vida. Ao retomar a noção de mundo da vida, ele compreende a hermenêutica não mais como atualizadora de sentido, mas como forma metodológica de validação de saberes por meio do julgamento pelo outro. Estar de acordo não é mais um diálogo acrítico com a tradição, no sentido de simplesmente aceitar as suas pretensões, mas submetê-la à possibilidade de reconhecimento por meio da apresentação 
de razões. Desse modo, o mundo da vida não é visto apenas como pano de fundo, como algo que está por detrás dos sujeitos, como era visto na tradição hermenêutica, mas também é algo que nos confronta e que necessita ser desproblematizado. O sujeito não apenas é visto como produto de tradições e da cultura instituída, mas estabelece uma relação de iniciação sempre renovada e que ocorre de maneira circular. Por isso, para ele:

a linguagem só é relevante do ponto de vista pragmático de que os falantes, ao empregar sentenças orientadas pelo entendimento, estabeleçam referências ao mundo - e isso não apenas direta (...) mas de maneira reflexiva (HABERMAS, 2012, p. 190).

Desse modo, aquilo que a fenomenologia husserliana legou, como dado primeiro, como trato ingênuo com o mundo, que constitui a relação originária do ser com o mundo, recebe em Habermas, e mais ainda em Honneth, o elemento da confrontação crítica. Os falantes "não fazem mais referência pontual a algo no mundo objetivo, social ou subjetivo, mas relativizam sua exteriorização de acordo com a possibilidade de que sua validade seja contestada por outros atores" (HABERMAS, 2012, p. 191). Portanto, o mundo da vida é compreendido não apenas como recurso, mas é algo tópico que desafia o ator.

O mundo vivido torna-se assim o limite referencial da possibilidade do entendimento. Ele é seu correlato, ou seja, "fonte de definições situacionais que podem ser pressupostas pelos partícipes como se fossem isentas de problemas" (HABERMAS, 2012, p. 138). Desse modo, a teoria de Habermas introduz o elemento comunicação (processo de entendimento) para explicar como as ações são guiadas pelo acordo recíproco frente ao mundo da vida, para enriquecê-las e torná-las, de certo modo, autônomas dos interesses do sistema. Habermas tenta, desse modo, associar essas duas tradições: a hermenêutica, como compreensão pela linguagem, a partir do mesmo pano de fundo, busca superar o dualismo kantiano de fenomenológico e inteligível; e a revisão crítica procura evitar compreensões distantes do mundo da vida. Por isso, se utiliza da ideia de pretensões de validade criticáveis, ou seja, os enunciados interpretativos são sempre colocados de forma hipotética, sendo reconhecidos apenas quando as "condições de validade de uma exteriorização tenham sido cumpridas" (HABERMAS, 2012, p. 83). 
A hermenêutica habermasiana acrescenta ainda a ideia de que há um mundo da vida construído pela linguagem (alcançado por processos de entendimento) que precisa ser compreendido.

Tal "mundo da vida constitui o horizonte de processos de entendimento por meio dos quais os envolvidos se embatem ou se põem de acordo sobre algo que está no mundo objetivo, em seu mundo social ou num mundo subjetivo em particular" (HABERMAS, 2012, p. 245).

Desse modo, os enunciados interpretados são colocados como pretensões de validade que serão avaliadas segundo razões buscadas nesse horizonte:

o intérprete entende o significado de um texto na mesma medida que obtém clareza sobre por que 0 autor se sente autorizado a propor determinadas asserções (como verdadeiras), reconhecer determinados valores e normas (como corretos), externar determinadas vivências (como verazes) (HABERMAS, 2012, p. 246).

Desse modo, há problemas diante do mundo da vida quando a comunicação está distorcida (levando à submissão de indivíduos e grupos sociais). E se há distúrbios na comunicação é porque não há o cumprimento de "(algumas) condições linguísticas para o entendimento entre (pelos menos) dois participantes da interação" (HABERMAS, 2012, p. 244). Por isso, Habermas vai dizer que é preciso interpretar os processos de entendimento para compreender o sentido das ações realizadas. No entanto, verifica que a compreensão do sentido depende do julgamento do intérprete, sendo essa a possibilidade de desmascarar os interesses ideológicos (tal é o passo que ele dá em relação à hermenêutica tradicional). Habermas acrescenta o fator "julgamento" (sim ou não) por parte do intérprete, tendo em vista que a hermenêutica tradicional não é crítica o suficiente para identificar as comunicações distorcidas. $O$ giro se dá como necessidade de se desvendar o sentido diante dos diferentes mundos, que Habermas alimenta com a necessidade de julgamento crítico em favor da universalidade. Não se trata mais simplesmente de um sujeito crítico da realidade social, mas de intérpretes capazes de dizer sim ou não frente às manifestações simbólicas que emergem a partir da referência aos três mundos que constituem o mundo da vida - objetivo, social e subjetivo. 
Sendo assim, diante da crítica dos pioneiros da escola de Frankfurt às normatizações impostas pela razão cognitivo-instrumental, Habermas elabora o conceito de razão comunicativa como tentativa de reconstruir as regras sociais diante das necessidades do entendimento. Desse modo, em vez de renunciar às normatizações, Habermas busca identificar novas formas de regramento na ação orientada ao entendimento (agir comunicativo). São regras não impositivas, nem dominadoras, tendo em vista que são constituídas nas próprias relações intersubjetivas dos sujeitos que buscam se entender sobre algo.

Seguindo os pressupostos de uma orientação racional vinda do mundo da vida, Habermas alerta para algumas qualidades formais que as tradições culturais devem apresentar caso busquem se entender sobre algo no mundo. Elas precisam, basicamente,

disponibilizar concepções formais para os mundos objetivo, social e subjetivo; precisam admitir pretensões de validade diferenciadas (...) e ainda estimular o alcance de uma diferenciação de posicionamentos básicos. Aí sim as externalizações simbólicas podem ser geradas em um nível formal em que elas estejam sistematicamente vinculadas a razões e acessíveis a um julgamento objetivo (HABERMAS, 2012, p. 140).

Além disso, necessitam

permitir-se uma relação reflexiva consigo mesmas; precisam despir-se de seu dogmatismo a ponto de poder pôr profundamente em questão as interpretações herdadas da tradição e submetê-las a uma revisão crítica (HABERMAS, 2012, p. 141).

Existe assim a possibilidade de uma racionalidade comunicativa na formação, a partir do conceito do mundo da vida, entendido como amortecedor dos desacordos.

Para Baynes essa ideia é expressa em Habermas da seguinte maneira:

De modo mais específico, de acordo com o modelo de Habermas, a normatividade não depende de uma noção voluntarista da capacidade de um agente para fornecer a si mesmo uma lei. Ao contrário, é no 
interior de práticas sociais de 'reconhecimento recíproco', nas quais os indivíduos se atribuem mutuamente o estatuto de fornecedoresde-razão, que a noção de um agente como um 'fornecedor-de-lei' (e, portanto, a fonte da normatividade) deve ser particularmente situada (BAYNES, 2008, p. 239).

Percebe-se o quanto Habermas, por um lado, é devedor de Kant, pois a capacidade de o indivíduo estabelecer a sua própria lei, característica da filosofia do sujeito, migra para as práticas intersubjetivas de reconhecimento recíproco. Por outro lado, com tal movimento ele se aproxima embrionariamente das formulações de Honneth, ao propor a ideia do reconhecimento como mola propulsora para a ação, ou melhor, como telos da ação. É nesse contexto que todo o resto, inclusive as pretensões de validade criticáveis, ganha sentido, pois segundo Baynes (2008, p. 241) esclarece mais adiante:

O objetivo ou o telos da ação comunicativa não é expresso ou realizado em uma tentativa de influenciar os outros, mas antes na tentativa de alcançar um acordo ou entendimento mútuo com um ou mais atores acerca de algo no mundo.

Essa forma de reconstruir as condições já pressupostas na convivência humana torna possível alcançar o entendimento no mundo, ou melhor, entender-se com o outro sobre algo. O potencial crítico passa a ser visto pela postura do outro frente à pluralidade das manifestações possíveis.

\section{Os (des)caminhos da racionalidade comunicativa}

Apesar de seguidor de Habermas no que diz respeito à valorização da intersubjetividade da compreensão, Honneth (2009) explica que a troca, realizada por Habermas, do paradigma da produção, até então central na teoria crítica, para o paradigma da compreensão, por um lado representou a principal contribuição na evolução da teoria, mas por outro concorreu para afastar a questão do conflito social. Outra constatação diz respeito à trajetória da teoria crítica, que desde Horkheimer, Habermas estava se dando às costas dos sujeitos implicados. Na tentativa de avanço a essa problemática, Honneth (2003) apresenta o paradigma da luta por reconhecimento, explo- 
rando a ideia da sua existência entre sujeitos socializados. Assim, trabalha na linha de que a autorrealização e a autocompreensão do sujeito só se dão mediante a efetivação de um reconhecimento proveniente de seus pares dentro dos grupos sociais. E qualquer coisa que constitua um empecilho ao reconhecimento, como condição de autorrealização, passa a ser motivo pelo qual os sujeitos se organizam para restabelecer e reivindicar novamente uma autorrealização positiva no seio da sociedade mais ampla.

Segundo Holmes (2009), enquanto Habermas fixa um critério formal (ou ideia reguladora) de justificação moral, diferentemente em Honneth, o núcleo de impulso da luta por reconhecimento são as experiências descritas no horizonte teórico que, ao mesmo tempo, podem ser consideradas patológicas ou injustas socialmente na perspectiva de compreensão dos próprios sujeitos implicados.

Daí por que as lutas sociais, motivadas por situação de desrespeito, só podem de fato se transformar em movimentos de resistência política se, ao mesmo tempo, o entorno político e cultural for considerado favorável. "Evidentemente", como afirma Holmes (2009, p. 134), "tais pretensões chamam a atenção para um radical giro historicista dado por sua teoria, marcadamente na dimensão interpretativa das contingências organizatórias de lutas sociais por reconhecimento" (HONNETH, 2004a, p. 358).

Nesse sentido, Holmes chama atenção para o fato de uma possível formulação da teoria crítica nos termos da evolução das lutas sociais por reconhecimento. Assim, seguindo na trilha aberta por Honneth, alerta que o ponto para novas articulações é o sujeito que interpreta mesmo que movido no horizonte de uma tradição: cada interpretação nova amplia os espaços sociais de expressão da sua própria atividade. Essa tarefa se dá na procura da confirmação social de seus sentimentos morais, os quais são articulados gramaticalmente na semântica social. Desse modo, a teoria crítica passaria a auxiliar nos processos de interpretação em duas frentes: primeiro, esclarecendo possíveis caminhos de autodeterminação do sujeito totalmente isenta de qualquer constrangimento, e, segundo, apoiando na autocompreensão do próprio sujeito no interior dos grupos sociais, o qual faz determinadas escolhas, repletas de significados, na busca da autorrealização. 


\section{Retomada do conceito de reificação em Axel Honneth}

Em sua obra Reificación: un estudio en la teoría del reconocimiento, Honneth propõe uma reatualização do conceito de reificação que passa a ser entendido como o "esquecimento do reconhecimento". Segundo a sua avaliação, na estrutura do reconhecimento existe uma capacidade prévia que identifica e valoriza o significado que têm as pessoas e as coisas. Afastarse dessa capacidade é ensejar a reificação. Para tanto, o autor realiza uma exegese do conceito, identificando-o como contraposto à ideia de reconhecimento. As implicações desse estudo têm significativa importância para a questão educacional, visto que a educação, entendida num sentido crítico e emancipatório, só se torna possível numa esfera de reconhecimento mútuo.

Qualquer tentativa no sentido de esclarecer a questão acerca de se o conceito de reificação continua sendo útil na atualidade, é sensato dirigir a atenção, segundo Honneth, em primeiro lugar à análise clássica de Lukács. O atual filósofo frankfurtiano explica que quando, seguindo Marx, Lukács afirma que a reificação não significa mais do que o fato de uma relação entre pessoas adquirir um caráter de coisa, ele está atendendo à compreensão habitual ontologizante do conceito de reificação. Entretanto, segundo Honneth,

no está claro aqui en el caso de una reificación tal se trata simplemente de un error categorial epistêmico, de una acción moralmente reprochable o de una forma de práxis distorsionada en su totalidad (HONNETH, 2007, p. 24).

As argumentações de Lukács pretendem assim transpor a teoria do fetichismo da mercadoria, de Marx, para explicar como o fenômeno da reificação passa a se constituir como uma tendência abrangente que avança na direção de todas as esferas da vida social. Em consequência disso, Lukács chegaria àquilo que Honneth considera a tese central do estudo dele, a saber, que no capitalismo a reificação se transformou na segunda "natureza do homem". Nessas circunstâncias, o cenário reificante coloca o sujeito em condições de estado meramente contemplativo diante da realidade circundante - um observador sem influência, indiferente. Por isso: 
En vez de considerar como cuestión primordial las modificaciones que la reificación produce en los objetos aprehendidos, observa en un primer momento las transformaciones que el sujeito que actúa debe experimentar en si mismo (HONNETH, 2007, p. 28).

Nesses termos, é chamada a atenção para os efeitos que as formas sociais reificadoras têm sobre a interioridade constitutiva da subjetividade do indivíduo.

O desenvolvimento da crítica da reificação feita por Lukács oferece, desse modo, de forma implícita duas alternativas contraditórias para compreender seu recurso como forma "verdadeira", não distorcida de práxis humana. Na versão oficial são criticadas as práticas de reificação como uma "segunda natureza" - a contraposição apresentada é o ideal de uma práxis abarcadora, na qual toda a realidade é gerada em último término pelo trabalho da espécie. É preciso destacar que esse modelo apoia-se em premissas idealistas, dado que Lukács se ampara na ideia de atividade autoprodutiva e espontânea do espírito, conforme desenvolvida por Fichte. Assim, Honneth diz que esse modelo também fracassa porque nem toda a existência de objetos envolve caso de reificação. É só na segunda abordagem, não oficial, que parece tomar mais sério a crítica da reificação definida como práticas e atitudes reduzidas, nas quais o sujeito se encontra em estado de mero observador. Nessa segunda alternativa, a contraposição à reificação baseia-se num ideal de práxis que está caracterizado pelas qualidades da "participação ativa" e do "compromisso existencial". Nesse caso, não há nenhum apoio de matiz idealista, pois "se trata de una forma especial de la interación ante que una actividad productora de mundo" (HONNETH, 2007, p. 38).

O filósofo frankfurtiano esclarece ainda que Lukács e Heidegger concordam em "destruir" a ideia segundo a qual um sujeito epistêmico se enfrenta com o mundo de maneira neutra. Heidegger segue o caminho da fenomenologia, com a analítica existencial, tentando mostrar que a execução da vida cotidiana está em aberto. Normalmente não se enfrenta a realidade na postura de um sujeito cognoscente, mas se está tão pendente a dominá-la que ela é dada como um campo de significação de práticas. $\mathrm{O}$ conceito que Heidegger usa para caracterizar a estrutura dessa relação é o de "cuidado". É justamente nesse ponto conceitual que Honneth vê um elo com as ideias de Lukács, quando este trata do conceito ampliado de "práxis" como contra- 
posição à "conduta meramente observadora" - típica do estado de reificação. Assim, seguindo Honneth, é possível dizer que tanto para Lukács quanto para Heidegger as condições reificantes de vida dissimulam a efetividade genuína da ontologia social dos homens, pois:

Como Heidegger, Lukács también supondría que las condiciones reificadas sólo constituyen un marco de interpretación falso, un velo ontológico detrás del cual se esconde la facticidad de la forma efectiva de la existência humana (HONNETH, 2007, p. 43).

Para estabelecer a pertinência do conceito de reificação na atualidade, o primeiro passo de Honneth é justificar a premissa básica dessa empreitada teórica. Nesse sentido, esclarece a tese segundo a qual a atitude de "cuidado" possui uma preeminência não somente genética, mas também conceitual face à apreensão neutra da realidade. No segundo passo quer, recorrendo ao contributo teórico de Dewey, substituir cautelosamente o conceito heideggeriano de cuidado pela categoria hegeliana do "reconhecimento". Portanto, Honneth está convencido de que é possível fundamentar a tese de que na relação do homem consigo mesmo e com o mundo, a postura de reconhecimento, precede genética e categorialmente a todas as outras atitudes. Dessa forma, ele traz para essa exegese do conceito algumas proposições de John Dewey. Neste momento, apresenta-se um ponto vital no desdobramento de sua tese central, afirmando que Dewey esboçou no vocabulário de sua teoria uma concepção de relação original do homem com o mundo, e, de modo inesperado, isso se assemelha em muitos aspectos às premissas de Lukács e Heidegger.

Honneth explica que as reflexões de Dewey desembocam na afirmação de que toda compreensão racional da realidade está ligada previamente a uma forma holística da experiência, em que os dados de uma situação são acessíveis qualitativamente a partir de uma perspectiva de compromisso interessado. Com isso, o intento de Honneth é explorar essa questão de modo a alcançar uma justificação fundamental tanto para a transição do conceito de "cuidado" para o de "reconhecimento," quanto também para demonstrar a primazia de tal reconhecimento sobre todas as atitudes cognitivas frente ao mundo. Desse modo, o construto teórico de Honneth tem por escopo reabilitar o conceito de reificação na atualidade, trazendo a ideia de reconhecimento 
como o ponto crucial para o qual as concepções de "compromisso prático" (Dewey), "cuidado" (Heidegger) e "implicação" (Lukács) convergem sob o mesmo princípio - primordial, a saber, a precedência de um interesse existencial pelo mundo.

As suas argumentações indicam ainda que, na nossa relação com o mundo, estamos envolvidos desde sempre com uma atitude de abertura, implicação e interesse, em que paira a "preeminência do reconhecimento sobre o conhecimento", como uma espécie de ímpeto motivador da nossa ação e da nossa capacidade de atribuir sentido e significado às coisas. Dalbosco (2011, p. 38) considera a existência de dois níveis de compreensão do reconhecimento na obra de Honneth: um, baseado na afecção espontânea, primordial e "fundante do reconhecimento elementar (prévio)" e, outro, "eminentemente social", designado como "reconhecimento recíproco", que tem por base as três esferas do reconhecimento, a saber, o amor, o direito e a solidariedade. Assim sendo, enquanto em Habermas a negação do entendimento com o outro redundou nas patologias da comunicação distorcida, Axel Honneth faz jus à ampliação dessa perspectiva, na medida em que a negação desse processo, isto é, a reificação, é entendida como "esquecimento do reconhecimento" (HONNETH, 2007).

Essa capacidade prévia de implicar-se com o mundo é de natureza afetiva e emocional. Isso constitui o rudimento que serve de base para uma "apreensão" cognitiva do mundo. Para demonstrar a preeminência ontogenética do reconhecimento frente ao conhecimento, Honneth discute certas investigações que foram realizadas com autistas. Ele quer enfatizar, seguindo essas pesquisas, que a capacidade que o adulto tem de abstrair, conhecer, comunicar e expressar o pensamento de forma lógica não é estritamente dependente de um processo de desenvolvimento cognitivo. Ainda que isso dependa de certas condições neurais e fisiológicas, antes isso é tributário de uma forma de implicação prévia com o mundo, que inicialmente ocorre com o desenvolvimento de um sentimento de união da criança com a pessoa de referência. Somente com uma identificação prévia tal o sujeito permite deixar-se mover ou motivar pela presença do outro concreto, de modo que venha a seguir, impulsionado por grande interesse, os movimentos e atitudes de uma segunda pessoa. É a ausência desse processo que não permite ascender ao conhecimento; eis aí uma das grandes características da postura autista. Assim, o autista é considerado cego não por carência cognitiva, mas 
sim porque, em seu isolamento do mundo, não consegue desenvolver-se afetivamente de forma primordial (HONNETH, 2007, p. 68).

Considera igualmente que Adorno apresentou reflexões desse tipo ao longo de sua obra, as quais destacam uma espécie de precedência afetiva do conhecimento. Nesse caso, essa questão diz respeito ao mesmo processo de descentração referido pelos outros autores da psicologia evolutiva (Peter Hobson e Michel Tomazello), o que constitui o esquema inicial de desenvolvimento dos processos de aprendizagem da criança, qual seja, a forma de implicação existencial e que se dá num plano afetivo com o outro. Somente assim a criança experimenta sua perspectiva do mundo de maneira significativa. Honneth esclarece que provavelmente Heidegger e Dewey também tinham presente uma ideia de "preeminência" quando defendiam que a relação objetiva e epistêmica com o mundo era precedida por atitude de "cuidado" ou "involucramento existencial". Isso significa que, considerados na sua dimensão mais abrangente e profunda, os esforços cognitivos falham quando se perde de vista o "reconhecimento prévio". Ao passo que em Heidegger o conhecimento científico era derivado da atitude prévia que ele denominara de cuidado, em Dewey toda a investigação tem que estar consciente da "experiência qualitativa original" no mundo da vida, que jamais se pode esquecer, sob pena de perder de vista esse princípio regulador dos esforços de conquista do conhecimento. Por isso o conhecimento que não mantém uma linha de ligação com o reconhecimento resvala em reificação.

As contribuições de Cavell completam o argumento sistemático apresentado por Honneth na discussão sobre a reificação, que ele apresentou proeminentemente até um dado momento, no seu pequeno livro, sob o ponto de vista histórico com a interpretação das ideias de Lukács, Heidegger e Dewey. Esses, para ele, estavam convencidos de que o reconhecimento deve preceder ao conhecimento no campo social. E com as contribuições dos estudos dos autores da psicologia evolutiva deu-se sustento no sentido temporal ou genético à questão referente à tese da "preeminência do reconhecimento". Mas foi só recorrendo a Cavell que ele acreditou ser possível defender mais do que o sentido temporal, mas também o sentido categorial dessa tese.

Ao lembrar que em Lukács a reificação é tanto um processo como um resultado, e que ela designa o processo de uma perda, quando se dá a substituição de uma atitude original, correta por outra secundária, incorreta, conclui que aí se chega ao resultado desse processo e que isso constitui uma 
percepção ou uma forma de conduta reificada. Assim, por um lado, Honneth consegue apresentar, a partir de Lukács, boas razões para se crer na existência de uma atitude prévia de reconhecimento ou implicação, pelo menos no que diz respeito ao mundo dos fenômenos sociais. Mas, por outro, ele se depara com uma questão fundamental: "Como puede explicar Lukács el que se llegue a una perdida de esta forma de conducta original, si éstá supuestamente tan enraizada en la forma de vida del hombre"? (HONNETH, 2007, p. 85).

Então, se praticamente todos os processos sociais que impõem alguma forma de objetivação já se constituem em reificação, a sociabilidade humana teria se dissolvido. Honneth explica que essas questões são sequelas da estratégia conceitual desenvolvida por Lukács no momento em que equipara a reificação com a objetivação. Daí que, para o desenvolvimento ulterior de suas reflexões sobre a reificação, Honneth só deve investir naquelas que são concebidas de maneira diferente das de Lukács. Assim ele defende que, em vez de pensar como Lukács, no qual o reconhecimento e o ato de conhecer, mediante processos objetificadores, estariam em estados de incompatibilidade constante, prefere colocar a argumentação em outros termos, num ponto de vista mais abrangente:

a las formas sensibles al reconocimiento, por un lado, corresponden, por outro lado, formas del conocimiento en las que se há perdido la capacidad de perciber su origen en el reconocimiento prévio (HONNETH, 2007, p. 91).

Perseguindo as intenções de Lukács num nível mais alto, Honneth (2007, p. 91) explica que:

Podríamos entonces llamar "reificación" a tal forma del "olvido" del reconocimiento"; y con ello nos referimos al processo por el cual en nuestro saber acerca de otras personas y en el conocimiento de las mismas se pierde la conciencia de en qué medida ambos se deben a la implicación y el reconocimiento prévios.

Daí por que o novo conceito-chave de reificação esclarecido por Honneth ligado à ideia de esquecimento tem a ver com o fato de que, ao lidarmos com o conhecimento, perdemos a capacidade de perceber e sentir que a própria constituição deste se deve à adoção de uma "postura de reconhecimento". Por 
isso, acabamos por desenvolver a tendência de perceber as outras pessoas como coisas ou objetos insensíveis. Honneth se pergunta, então, como é possível que o reconhecimento prévio seja esquecido tanto geneticamente como categorialmente durante nossos envolvimentos diários com operações que envolvem o conhecimento? Ele explica que esquecimento não tem o sentido usual de subtrair da consciência ou desaprender alguma coisa, antes se trata de uma classe de diminuição da atenção que leva o reconhecimento a ser passado a um segundo plano até que se perca de vista. Em suma,

La reificación en el sentido de un "olvido del reconocimiento" significa entonces, en la ejecución del conocer, perder la atención para el hecho de que este conocimiento se debe a un reconocimiento prévio (HONNETH, 2007, p. 96).

Diante dessas questões, Honneth coloca para si o desafio de reatualizar o conceito de reificação de modo que as circunstâncias aludidas sejam entendidas como uma atrofia ou uma distorção de uma práxis original em que o ser humano adota uma relação de implicação, de respeito a si mesmo, ao outro e do seu entorno.

\section{Filosofia da educação no movimento de reconhecimento}

Como vimos até aqui, desde a explicitação da normatividade até a constante atenção com a dimensão crítico-social da educação, essas tarefas são cumpridas de modo satisfatório no giro do reconhecimento do outro na teoria crítica. Em ambos os autores aqui tratados há uma migração para o idealismo, mas sem o apelo ao transcendental do conhecimento - em Habermas, para Kant, e em Honneth para Hegel - pois se trata agora de pensar nas condições e possibilidades de compreensão da ação no interior da teoria social. Nesse sentido, pensando essas questões no campo educacional, podemos afirmar que a educação, como fenômeno situado na prática social, mais do que nunca precisa estar atenta para as condições que levam à manifestação de processos reificantes no seu contexto ou dos princípios formativos, principalmente quando o conceito de reificação passa a denotar "esquecimento do reconhecimento". A ideia do reconhecimento do outro se torna, desse modo, um elemento fundamental para a redefinição crítica de políticas sociais e culturais, 
podendo também inspirar outra relação entre filosofia e educação. Por isso, cabe à filosofia da educação, sustentada na complementação da crítica à ideia do reconhecimento, algumas tarefas, a seguir descritas.

\section{Tarefas da filosofia da educação no reconhecimento do outro}

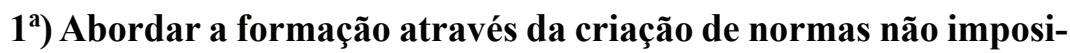
tivas, portanto constituídas pela própria condição humana de buscar o reconhecimento do outro.

A ideia de formação se expressa como constituição linguística sempre suscetível de transformação ou desabilitação, pois depende das relações de reconhecimento. $\mathrm{O}$ pensamento tradicional tendeu a negar à racionalidade a possibilidade de reflexão e experiência do outro, por conta do fechamento na filosofia do sujeito. Já o pensamento crítico de Habermas apreende a possibilidade de a racionalidade se abrir a essa perspectiva por meios comunicativos, enquanto Honneth introduz os pressupostos de uma vida social baseada nas lutas pelo reconhecimento. É o seguimento de uma crítica que vai se aperfeiçoando em favor da ampliação de um sistema normativo, constituído pela prática de escutar, entender e reconhecer mutuamente.

As críticas de Habermas e Honneth inspiram a ideia de uma filosofia da educação em que não é mais possível um modelo de formação objetivo, subjetivo, técnico ou crítico exclusivamente, mas modelos constituídos a partir das necessidades de entendimento e/ou reconhecimento. Não existe uma normatização puramente teórica a ser seguida, mas normatizações estabelecidas por intermédio da necessidade de desproblematizar o mundo da vida compartilhado, que, para Habermas, é constituído por regras objetivas, subjetivas e sociais. A possibilidade de aprendizagem no coletivo remete diretamente ao fato de que todos possuem passaporte para se fazer participantes das decisões, com base não apenas nas necessidades pessoais ou de grupos, mas também, e principalmente, nas lutas sociais em prol do reconhecimento. 


\section{$2^{\circ}$ ) Interpretar a natureza constitutiva da manifestação de situações reificantes apresentando caminhos alternativos.}

Na nova acepção da ideia de reificação, enquanto esquecimento do reconhecimento, manifesta-se justamente a quebra do vínculo do conhecimento com o reconhecimento, na medida em que o primeiro se torna incompatível com o segundo ou acaba por esquecê-lo. Nesse sentido, uma das atribuições da filosofia da educação é tornar claras as circunstâncias que permitem ao processo educativo apoiar-se numa base prévia de reconhecimento mútuo e elementar, na qual estão amparadas as relações de confiança e afeto. Sem isso não haverá possibilidades de construir um lastro axiológico de sustento ao conhecimento e o cultivo da dimensão cognoscitiva.

Sendo assim, a filosofia da educação por um lado tem que estar a serviço da denúncia e da interpretação daquilo que constitui os mecanismos de reificação humana. E, por outro, tem que estar disposta a destacar que, no curso de apropriação da cultura e da ciência, o elemento humano representa a significação máxima da vida social, na qual nenhuma teoria ou proposta política pode sobreviver eticamente se prescindir do "reconhecimento prévio elementar". Daí a necessidade de uma frequente reelaboração das experiências formativas para não se perder de vista a perspectiva do outro, com base na relação intersubjetiva.

\section{$\left.3^{\mathrm{a}}\right)$ Questionar estruturas assimétricas de reconhecimento entre teoria e prática no campo da formação.}

A estrutura normativa do reconhecimento recíproco poderia auxiliar a reverter os dilemas da compreensão separada da relação teoria e prática na formação. A relação teoria e prática constitui o eixo básico da formação inicial do professor, no entanto, ao privilegiar o polo da prática em detrimento da teoria, a chamada Pedagogia das Competências esvaziou a prática de sentido e o significado da educação promovida aos auspícios da reflexão sobre a formação mais ampla. Corresponder ao desafio de repensar uma estrutura comunicativa ou simétrica de reconhecimento entre teoria e prática na formação e, assim também, entre universidade e escola, assenta-se num processo de interatividade, interdependência e correspondência recíproca na construção de novos conhecimentos no campo da formação, dos saberes 
docentes e do aperfeiçoamento dos cursos de licenciatura. A perspectiva simétrica ou comunicativa do reconhecimento entre teoria e prática requer o entendimento de que o problema da exclusão social, por exemplo, se relaciona com fatores mais amplos, não submetidos à lógica das competências e habilidades simplesmente.

\section{$4^{\text {a) }}$ Auxiliar na compreensão mais aprofundada das políticas de inclusão ou políticas afirmativas atualmente em curso.}

$\mathrm{O}$ estado tem se esmerado, em certo sentido, em promover políticas de reconhecimento das identidades, pelas quais os sujeitos são reconhecidos enquanto pertencentes a um grupo ou coletivo. Embora isso ainda não abarque as singularidades, as políticas públicas de educação brasileiras estão buscando a inclusão da diversidade, procurando garantir o acesso ao ensino superior mediante as políticas de cotas para deficientes, indígenas, afrodescententes (minorias étnicas) e para alunos egressos de escolas públicas. No entanto, tais políticas não podem ficar apenas no nível da garantia do acesso, com a justificativa republicana da criação da igualdade de oportunidades. Se assim for, o reconhecimento do outro vai ocorrer somente de forma superficial, limitado apenas ao seu aspecto de entrada no sistema. Se não houver uma preocupação com a sua permanência no sistema de ensino, isto é, com o acolhimento em sua plenitude, as políticas de cotas correm o risco de estigmatizar a diferença. Esse é um forte limitador, um ponto de resistência ou um nó das políticas de inclusão que a filosofia da educação pode ajudar a desatar, pois o fracasso escolar tem que ser trabalhado na sua causa que não aparece, valorizando elementos da cultura local, mas sem cair no relativismo. É um novo modo de olhar que inspira uma formação baseada na possibilidade de ampliação da inclusão social, tendo como alicerce das avaliações normativas o reconhecimento do diferente diante de um sistema objetivo e de valores compartilhado por todos.

5) Analisar as metáforas subjacentes aos modelos formativos de inclusão propostas pelas diversas teorias da educação.

Influenciada por um tipo de filosofia com viés platônico, pois "o idealismo preparou nosso olhar para reconhecer o idêntico", mas não para "lidar 
com o outro" (HERMANN, 2011, p. 140), a educação operou historicamente filiada a discursos com viés em dois sentidos básicos. Primeiro, incentivada pela alegoria da caverna platônica e, portanto, mais atenta à busca do elemento "racional", ela acabou virando as costas para as diversas imagens que transitam no discurso filosófico e pedagógico, prestando pouca atenção às analogias e metáforas que moldam seus esquemas de compreensão. E, segundo, a educação esteve interessada em influenciar o outro, tendo em vista a realização desse ideal (platônico) distante da realidade vivida, muito antes de ouvi-lo ou acolhê-lo, o que seria, justamente, a reivindicação do reconhecimento. $\mathrm{O}$ distinto de si mesmo foi visto, nesse caso, como objeto a ser convertido à minha verdade, à verdade da filosofia do sujeito, resultando em patologia e exclusão das diferenças. É por isso que a pluralidade se instalou no discurso da educação, não apenas para fazer frente à necessidade de contemplar a visão descentrada de mundo, característica da modernidade, mas especialmente em função da crítica à razão teleológica e seus nefastos efeitos, isto é, "devido aos comprometimentos da razão com o poder opressivo sobre os homens, da hostilidade da razão à vida" (SEVERINO, 2006, p. 629). A crítica ao saber cognitivo-instrumental que regrava de forma totalitária as ações pelo leme da técnica foi substituída pela normatização via social. Trata-se agora de alavancar essa possibilidade com o resgate dos sujeitos implicados nos processos de melhorias da educação, sem deixar que se recaia na ausência de normatização.

\section{$6^{\text {a) }}$ Repensar a fragmentação interpretativa das investigações através da validação dos saberes produzidos pelo julgamento e/ou re- conhecimento do outro.}

A proposta propicia à área da educação a possibilidade de repensar a fragmentação interpretativa das investigações, centrada ora no natural, ora no social ou então no psicológico, para atuar diante da necessidade das práticas universais, reforçando desse modo os laços comunicativos e o reconhecimento entre os diferentes. Ou seja, permitir que as produções investigativas solitárias ou dos grupos possam ser submetidas à aceitação ou não de outros pesquisadores, tendo como base não apenas a vertente do econômico-social, mas também a vertente do mundo da vida constituído pelo subjetivo, social e objetivo. Trata-se de uma proposta comprometida 
com a manifestação da multiplicidade interpretativa que não abandona a preocupação com o universal do qual fazemos parte.

\section{Aspectos conclusivos}

Cada vez mais, a filosofia da educação vem sendo discutida por uma pluralidade maior de perspectivas paradigmático-epistemológicas, trazendo para a área propostas fundamentadas nas mais diversas justificativas - das naturalistas até as sociais. Não tem sido raro se deparar com dissensos acerca dos propósitos da formação, haja vista a descentralização da compreensão em torno de questões importantes como subjetividade, objetividade, realidade, teoria, prática etc. Apesar de a descentralização ser positiva, no sentido de significar um maior reconhecimento da pluralidade interpretativa, tais dissensos trouxeram dificuldades para a formação, tendo em vista as discrepâncias conceituais no tratamento das mesmas questões. Perguntamos: se não é mais possível apreender a totalidade fundamentadora, devido à descentralização já consolidada da compreensão, como podemos incorporar a pluralidade interpretativa na formação sem correr o risco de cair no relativismo? Como evitar que monopólios interpretativos sejam colocados antes mesmo de haver discussões nas ações formativas?

Trata-se de questões difíceis de responder, tendo em vista que qualquer tentativa teórica pode significar mais um viés interpretativo. No entanto, mesmo correndo esse risco, buscamos discutir algumas saídas a essas questões a partir dos propósitos da racionalidade comunicativa, de Habermas, e, principalmente, da ideia do reconhecimento do outro, de Honneth. Diante do movimento de crítica da razão instrumental, do qual eles mesmos compartilham, buscam recuperar a possibilidade de a razão se desenvolver pelos seus aspectos intersubjetivos.

Nesse sentido, Habermas procura atender aos propósitos de uma sociedade emancipada, reconhecendo na comunicação entre os intérpretes a possibilidade do entendimento. Para que esse entendimento seja possível, aposta no conceito do mundo da vida como pano de fundo que ["acumula o trabalho interpretativo prestado pelas gerações precedentes; ele é o contrapeso conservador que se opõe ao risco de dissenso, que surge com todo o processo atual de entendimento" (HABERMAS, 2012, p. 139).] Entende os desacertos como patologias da comunicação que desconsidera os sabe- 
res pré-teóricos do mundo da vida. Contrário à perspectiva contextualista defendida por certas posições pós-modernas, o autor aposta na comunicação como possibilidade de alcance de validades mais universalizadas na condução dos problemas, sendo o mundo da vida o arcabouço formal que oferece orientações racionais para a ação.

Essa proposta pode contribuir para repensar a formação, pois permite guiar as decisões para além dos contextualismos interpretativos, tendo em vista os saberes do mundo da vida compartilhados por todos. Trata-se de uma possibilidade de aprendizagem comunicativa em que cada interpretação é entendida como hipótese criticável. Ou seja, a ideia é apanhar a pluralidade interpretativa como possibilidade de uma comunicação crítica bem sucedida voltada aos acordos. Desse modo, evitar-se-iam tanto o relativismo na área como a sobreposição de perspectivas interpretativas.

Enfim, pode-se dizer que Habermas e Honneth, por meio da possibilidade do reconhecimento, inauguram um modo próprio de pensar a questão normativa no ambiente pós-crítico à razão tornada instrumental. Para esses autores, não se trata de negar a probabilidade da existência de normatizações sociais, e, sim, de reavaliá-las segundo as necessidades dos sujeitos que agem diante do mundo da vida comum. As normatizações, antes orientadas pela crítica social à vertente lógico-instrumental do sistema, passam a ser constituídas pelas avaliações intersubjetivas baseadas nas formas de vida compartilhadas por todos. Desse modo, a filosofia da educação ganha um novo significado, tendo em vista a ideia de "formação" ganhar força como crítica social em favor da ampliação das relações de reconhecimento do outro.

\section{Referências}

ADORNO, T.; HORKHEIMER, M. Dialética do esclarecimento: fragmentos filosóficos. Rio de Janeiro: Jorge Zahar Ed, 1985.

BAYNES, K. A virada transcendental: o pragmatismo kantiano de Habermas. In: RUSH, F. (Org.). Teoria crítica. Aparecida, São Paulo: Ideias \& Letras, 2008.

DALBOSCO, C. A. Reificação, reconhecimento e educação. Revista Brasileira de Educação, Rio de Janeiro, v. 16, n. 46, p. 33-49, 2011. 
HABERMAS, J. Teoria do agir comunicativo: racionalidade da ação e racionalização social. Tradução de Paulo Astor Soethe. São Paulo: Martins Fontes, 2012.

. Lutas pelo reconhecimento no estado democrático constitucional. In: TAYLOR, C. Multiculturalismo: examinando a política do reconhecimento. Lisboa: Instituto Piaget, s. d.

HEGEL, G. W. F. Fenomenologia do espirito. Trad. Paulo de Menezes. 5. ed., Petrópolis: Vozes; Bragança Paulista: Ed. Universitário São Francisco, 2008. . Princípios da filosofia do direito. Tradução de de Orlando Vitorino. 2. ed., São Paulo: Martins Fontes, 1976.

HEIDEGGER, M. A caminho da linguagem. Petrópolis: Vozes; Bragança Paulista, SP: Editora Universitária São Francisco, 2003.

HERMANN, N. Breve investigação genealógica sobre o outro. Educação e Sociedade. Campinas, v. 32, n. 114, p. 137-149, 2011. Crossef $<<\mathrm{http} / /$ dx.doi.org/10.1590/S0101-73302011000100009>>

HONNETH, A. A irretrocedibilidade do progresso: a determinação kantiana da relação entre moral e história. In.: PERES, D. T.; MATTOS, F. C.; REPA, L. et al. (Org.). Tensões e passagens: filosofia crítica e modernidade. São Paulo: Esfera Pública, 2008.

. Luta por reconhecimento. A gramática moral dos conflitos sociais. Tradução de Luiz Repa. 2. ed., São Paulo: Ed. 34, 2003.

. Reificación: un estudio en la teoría del reconocimiento. Buenos Aires: Kaatz, 2007.

. Crítica del poder: fases en la reflexión de una teoria crítica de la sociedad. Madri: Machado Libros, 2009

HOLMES, P. Reconhecimento e normatividade: a transformação hermenêutica da teoria crítica. Revista Brasileira de Ciências Sociais, São Paulo, v. 24, n. 69, p. 129-145. 2009. Crossef $<<\mathrm{http} / / / \mathrm{dx}$.doi.org/10.1590/s0102$69092009000100009>>$

SANTOS, B. de S. Introdução a uma ciência pós-moderna. Rio de Janeiro: Graal, 1989. 
SEVERINO, A. J. A busca do sentido da formação humana: tarefa da Filosofia da Educação. Educação e Pesquisa, São Paulo, v. 32, n. 3, p. 619-634, set./dez. 2006. Crossef $<<\mathrm{http}: / /$ dx.doi.org/10.1590/s1517$97022006000300013>>$

Data de registro: $16 / 03 / 2014$

Data de aceite: $22 / 10 / 2014$ 